\title{
Terminal Degeneration and Synaptic Disassembly following Receptor Photoablation in the Retina of the Fly's Compound Eye
}

\author{
J. H. Brandstätter, S. R. Shaw, and I. A. Meinertzhagen \\ Life Sciences Centre, Dalhousie University, Halifax, Nova Scotia, Canada B3H 4J1
}

\begin{abstract}
A long-term objective of our studies on the first optic neuropil (or lamina) underlying the fly's compound eye is to explore how afferent photoreceptor synapses disappear during normal adult experience. To increase the frequency of this loss and the chances for its detection artificially, we have examined in this study the synapses during the degeneration of their presynaptic elements, the synaptic terminals of the receptor cells. This may be reliably procured by illuminating for $12 \mathrm{~min}$ with strong green light eyes that have received an injection of the dye sulforhodamine 101 (Picaud et al., 1988). The lesion is local and develops rapidly. Degeneration among terminals is progressive but asynchronous. There are several different types of degeneration, most interpretable as stages in a temporal progression after illumination-induced injury. Degenerative changes include shrinkage and darkening of terminals and mitochondrial swelling. Synaptic sites are lost in a defined sequence: (1) the T-shaped presynaptic ribbon disappears first; (2) the members of what is normally a tetrad of postsynaptic elements withdraw as an ensemble from the receptor terminal's membrane, and the surrounding epithelial glial cells extend between former preand postsynaptic partners; and (3) the postsynaptic elements then separate from each other. In the most rapidly affected terminals, the frequencies for those synaptic sites at which both presynaptic ribbons and postsynaptic elements remain intact decline by $85 \%$, even in the first $8 \mathrm{hr}$ postillumination.
\end{abstract}

Adult synaptic contacts are widely presumed to be in a state of dynamic flux (Barker and Ip, 1966; Cotman et al., 1981; Wernig and Herrera, 1986). Evidence for this view comes, in particular, from the altered synaptic frequencies that follow differential experience (e.g., Greenough and Chang, 1985) and from the observation of sprouting and retraction at the normal, intact, adult neuromuscular junction (e.g., Herrera et al., 1990; for review, see Wernig and Herrera, 1986). To pinpoint such possible changes among the highly characterized synaptic populations of the first optic neuropil, or lamina, of the fly's compound eye, we have examined the afferent sites of the lamina axon terminals of the six identifiable cells, R1-R6, that comprise the outer ring of photoreceptors in each ommatidium (Meinertzhag-

Received May 10, 1990; revised Feb. 4, 1991; accepted Feb. 6, 1991.

This work was supported by NIH Grant EY-03592 and NSERC Canada Grant A9593 to S.K.S. Members of this laboratory are members of the Canadian Centre of Excellence in Neural Regeneration and Functional Recovery. We wish to thank H. S. Seyan for skilled technical assistance.

Correspondence should be addressed to J. $H$. Brandstätter at the above address. Copyright (c) 1991 Society for Neuroscience 0270-6474/91/111930-12\$03.00/0 en, 1989). The synaptic site itself is a tetrad (Fröhlich, 1985). Each site incorporates four postsynaptic elements derived from some of the uniquely identifiable interneurons within each module, or cartridge, of the lamina. The four invariably include two output monopolar cells of the cartridge, L1 and L2 (Nicol and Meinertzhagen, 1982).

The number of synaptic contacts that each of the terminals R1-R6 makes, 200 or so in the young adult housefly Musca (Nicol and Meinertzhagen, 1982), is precisely regulated but not fixed. It increases during early adulthood, then decreases slowly thereafter (Meinertzhagen and Fröhlich, 1983). It also rapidly changes after recent reversals of exposure to light, light to darkness, or vice versa (Rybak and Meinertzhagen, 1990). Thus, on different occasions, synaptic contacts may either be lost from, or accrue to, the adult population.

Although the assembly sequence of tetrad sites is known (Fröhlich and Meinertzhagen, 1982, 1983), there is no detailed description of later synaptic loss in the adult. Indeed, the low rate of loss in the normal population diminishes the chance to capture such events, unless each event is long-lived. We have therefore studied synaptic disassembly during the period of an artificially elevated rate of synaptic loss following photodegeneration. Photodegeneration was procured by illuminating the receptor cell bodies through the normal optical path to their light-absorbing rhabdomeres, after first injecting the eye with sulforhodamine 101 (Picaud et al., 1988, 1990). The method allows cxamination of degenerating photoreceptor terminals and their normal neighbors in the lamina after a discrete lesion, with a precisely timed onset, to the retina. The results identify several stages of synaptic disassembly in the hours following photodegeneration, none of which has been described so far in normal flies.

\section{Materials and Methods}

Photodegeneration. Houseflies, Musca domestica (L.), were reared in continuous culture on a synthetic diet at $23^{\circ} \mathrm{C}$ under a regulated 13-hr: 11-hr light/dark cycle (Fröhlich and Meinertzhagen, 1982). Seven-dayold females were immobilized by chilling and mounted with wax by the dorsal thorax onto a holder on a small universal joint; the head was waxed to the thorax. The retina of the right eye was microinjected with $21 \mathrm{nl}$ of a $0.5 \%$ solution of the dye sulforhodamine 101 in insect Ringer's solution (Molecular Probes, Eugene, OR; Picaud et al., 1988), pressureinjected as small droplets of measured volume from a calibrated micropipcttc of tip diameter about $5 \mu \mathrm{m}$ (Shaw, 1990), through a hole made with a tungsten needle far ventrally in the cornea. After a variable delay of $10 \mathrm{~min}$ to $1 \mathrm{hr}$, a small patch of the eye (usually 7-9 ommatidia, 3-5 rows above the eye's equator, and 8-10 facets from its medial border) was epi-illuminated for $12.0 \mathrm{~min}$ at full intensity with green light from a mercury arc lamp (Osram $\mathrm{HB} 0 ; 50 \mathrm{~W}$ ), on the stage of a Zeiss ACM microscope; the beam was filtered through an excitation filter (560DF40) and dichroic beam splitter (DR590LP), both from 




Figure 1. Light intensity distribution in the plane of the eye falls off steeply outside the illuminating spot used to promote photodegeneration (open symbols). This was measured on the microscope stage with a moveable linear photodiode occluded by aluminum foil carrying a 26$\mu \mathrm{m}$ aperture, using the normal sulforhodamine filters, $25 \times$ objective, and spot size. Light flux density is practically independent of spot size, as shown by fully opening the aperture on the light source (solid symbols).

Omega Optical Inc. (Brattleboro, VT), to give a measured passband of $535-585 \mathrm{~nm}$. The effects of intense local illumination were monitored visually and usually photographed, and the treated flies were then dismounted and left unrestrained in cages under normal room lighting, where they survived readily. Following postillumination periods of 1 $\mathrm{hr}$ to $14 \mathrm{~d}$, their heads were fixed for electron microscopy.

The intensity profile of the experimental illumination was scanned on the microscope stage (Shaw, 1990), to determine whether light remained well confined to the intended spot. The profile fell away very steeply at the edges of the illuminated area (Fig. 1), though direct visual observation suggests that the blur is inevitably larger with the eye in place (Fig. 2).

Intensity calibration. Because the first report using sulforhodamine 101 for photodegeneration (Picaud et al., 1988), which formed our starting point, gave illumination intensities only relative to a biological standard, the threshold of which possibly varies, the light used to promote photoreceptor degeneration was calibrated in absolute terms. The photon content was measured by conventional methods directly on the stage of the microscope using a calibrated photodiode and accessory interference filters, via the $25 \times, 0.45$-NA plan objective used for photoablation.

To estimate the fraction of the output that might be caught by the dye, the absorption of aqueous solutions of sulforhodamine 101 (2-10 $\mathrm{mg}$ /liter) was measured with a spectrophotometer and used to weight the spectral emission of the optical system, after normalizing that spectrum to unity at its measured maximum, $585 \mathrm{~nm}$ : the effective photon input to the dye in the eye was then equivalent to $2.5 \times 10^{16}$ photons $(585 \mathrm{~nm}) \mathrm{mm}^{-2} \mathrm{sec}^{-1}$. The quantum capture efficiency of the dye in the eye is unknown, but because the quantum yield in solution is already $<1$, the effective photon catch must be less than the value quoted. Exposure of the optically neutralized eye to the unattenuated intensity of the filtered beam produced visible blurring of the outlines of the dyed rhabdomeres within about $30 \mathrm{sec}$.

The beam was also calibrated at the end of the experiments relative to the biological quasi standard used previously (Picaud et al., 1988, 1990), the threshold for screening pigment granule migration (PGMT)

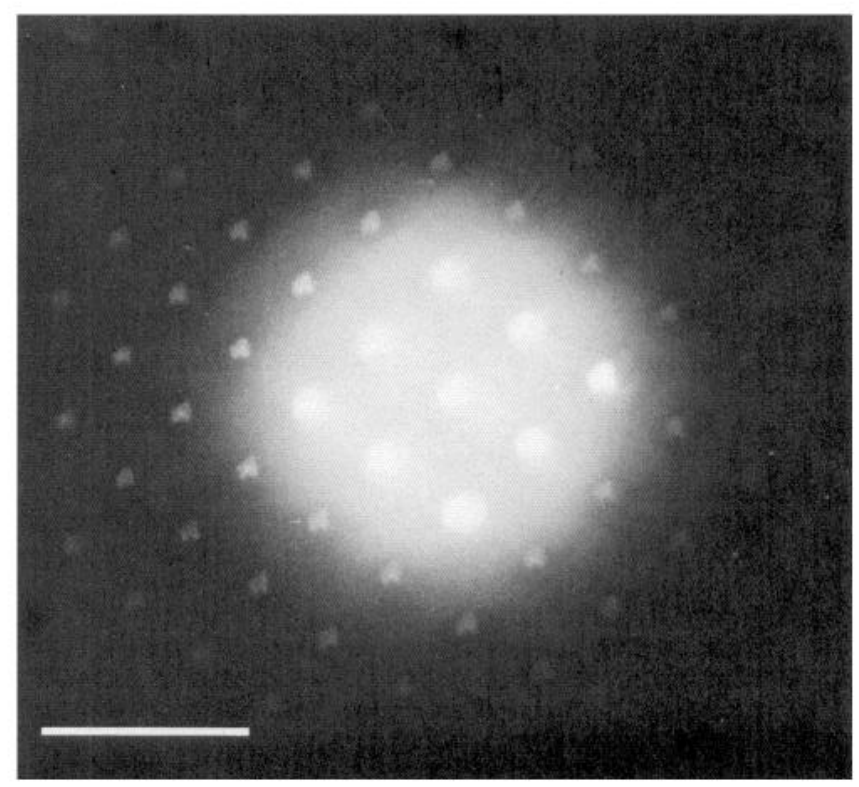

Figure 2. Epi-illumination view of an experimental eye, in the last minute of a 12-min period of full-intensity illumination with green light. Note the pattern of dyed photoreceptive rhabdomeres behind the facets within the illuminated aperture. Magnification, $400 \times$. Scale bar, $50 \mu \mathrm{m}$.

in the photoreceptors. Rhabdomeres were visualized by illuminating the eye antidromically through a $35-\mu \mathrm{m}$ fiber optic inserted through the back of the head capsule, after neutralizing the power of the facet lenses with nail polish (e.g., Franceschini and Kirschfeld, 1971). The fiber was powered from a $150-\mathrm{W}$ xenon arc lamp. The pupil response was induced in rhabdomeres R1-6 in the dorsal frontal eye by epiillumination from the same system used to promote photodegeneration, and the PGMT was estimated visually by attenuating this excitation with neutral filters. Threshold was reached between 3.3 and 3.0 optical density units attenuation in one female fly 7-8 d old. The best estimate is therefore that our 12-min, full-intensity experimental exposures were made at light intensities about 1000 -fold above the PGMT, fortuitously the same level quoted by Picaud et al. (1988), who attenuated a more powerful light source (Wunderer et al., 1989) but used a less efficiently absorbed wavelength $(546 \mathrm{~nm})$ and longer exposures $(30 \mathrm{~min})$. For reference, we calculate that the photon flux entering an R 1-R6 receptor during our experimental irradiations was approximately 100 -fold higher than the maximum level normally sustained by a fly viewing a bright sky, based upon spectral irradiance data for bright daylight (Wyszecki and Stiles, 1967, their Table 1.2) and spectral sensitivity data for R1R6 (e.g., Hardie, 1985, his Fig. 23), assuming a quantum capture efficiency of 0.7 at $495 \mathrm{~nm}$.

The phenomenology of uptake and photosensitization using sulforhodamine 101 and other markers is considered most recently by Picaud et al. (1990), and some ultrastructural correlates are given by Wunderer et al. (1989), but no clear mechanism has yet emerged.

Electron microscopy. The eyes were processed for thin-section EM according to our standard methods (Fröhlich and Meinertzhagen, 1982, 1983). The structure and frequency of the tetrad synapses found in the terminals of photoablated receptor cells, as well as the membrane perimeters of the terminals' profiles, were examined in single cross sections cut at $70 \mathrm{~nm}$; section thickness was standardized for counts of relative frequencies of synaptic profiles. Synaptic profiles were counted from electron micrograph prints of individual cartridge cross sections, as well as from the original $35-\mathrm{mm}$ negatives viewed in a Zeiss Jena microfilm reader (Dokumator DL2). The sizes of receptor terminals were measured from their profiles, traced from $35-\mathrm{mm}$ negatives projected upon an Apple graphics tablet used with an Apple II + computer and a morphometrics program (Scientific Microprograms, distributed through Marivac Ltd., Halifax, Nova Scotia). Control flies were also examined that had undergone the same injection procedure but that had not received illumination, and which consequently did not have photodegenerated receptor terminals. 


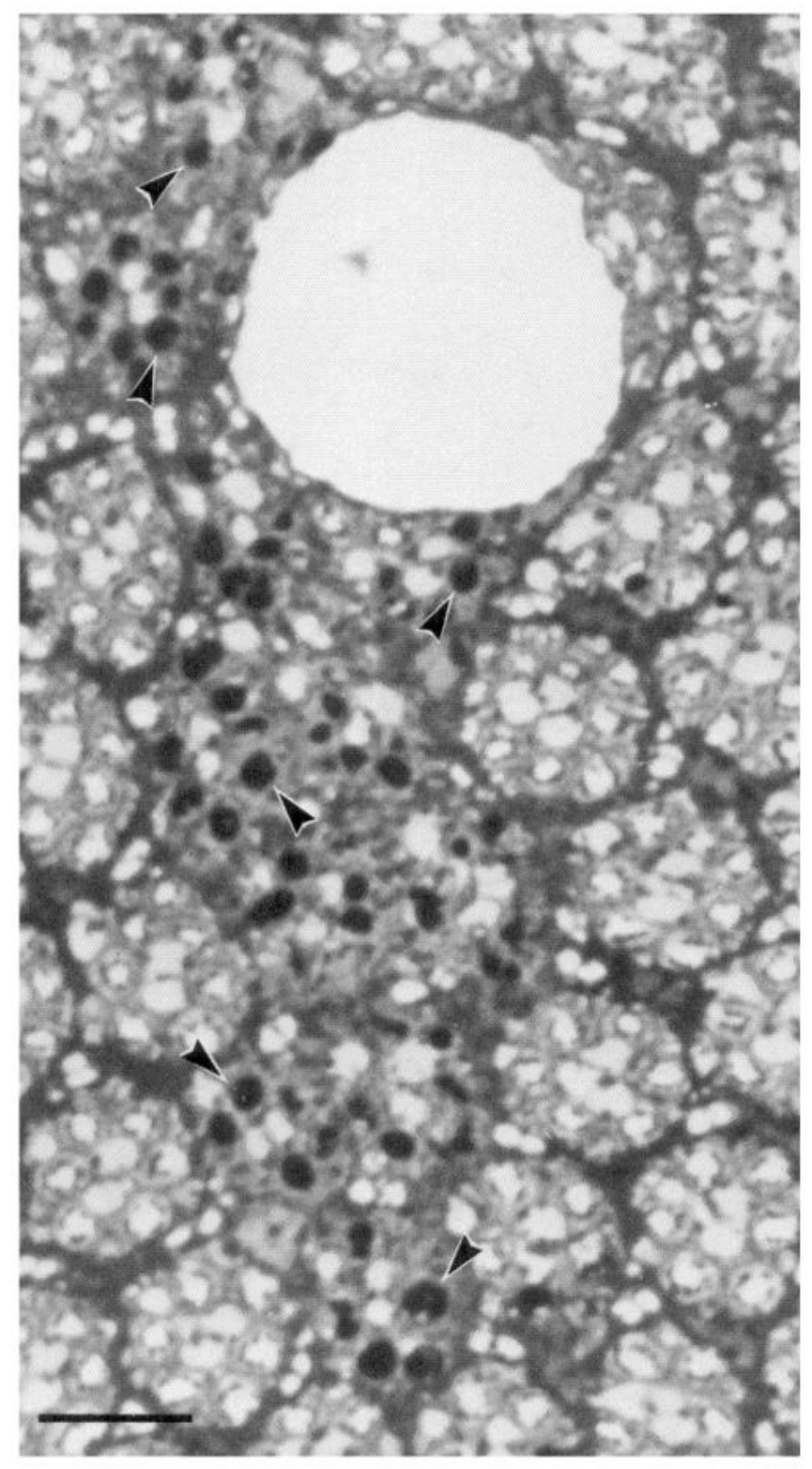

Figure 3. Section $(0.7 \mu \mathrm{m})$ of a 14-d-postillumination lamina showing a large hole, interpreted as the local vacuolization of a glial cell, surrounded by a dorsoventrally elongated strip of cartridges with darkened, degenerating terminals (arrowheads). Magnification, 1680×. Scale bar, $10 \mu \mathrm{m}$.

The control data actually used were from the experimental material (flies that were dye injected and illuminated) but from receptor cells that did not receive light and therefore did not show any degenerative changes.

Statistical methods. The correlations between synaptic frequencies or receptor terminal membrane perimeters and different stages of degeneration in the receptor terminals recovered at different postillumination periods were determined using the Spearman's rank-correlation test (Sachs, 1984). To compare either synaptic frequencies or receptor terminal membrane perimeters with the corresponding values in adjacent stages of degeneration among receptor terminals, the $U$ test of Wilcoxon, Mann, and Whitney (Sachs, 1984) was chosen.

\section{Results}

The results of photodegeneration

Viewing with low-intensity epifluorescence illumination (attenuation factor, 50-100), a position was quickly selected three to five ommatidial rows dorsal to the equator and about 10 facets from its anterior margin along the - x-axis (Braitenberg, 1967), away from the zone of possible damage caused by sulforhodamine 101 injection in the ventral eye. In most experiments, direct illumination was centered on a particular facet and the surrounding group of about eight others while focusing on the rhabdomeres, which fluoresced brightly with the amount of dye injected. The appearance of these rhabdomeres when next illuminated with full-intensity blue light became less distinct within about $30 \mathrm{sec}$, their fluorescence usually intensified, and by the end of $12 \mathrm{~min}$ exposure they often appeared swollen and hardly distinguishable above the now strong background fluorescent glow at the site of illumination, caused by dye uptake into retinal cells (Wilcox and Franceschini, 1984a,b; Picaud et al., 1988). The site of illumination could be routinely recognized later in the whole eye even after subsequent fixation and embedding, by its slightly darkened haloed appearance.

After 12 min exposure of the patch of retina at full intensity, the lamina subsequently revealed a zone of affected cartridges at the expected point. This was often a dorsoventrally elongated strip of mixed damaged and undamaged terminals; in one case examined in detail, the pattern of cartridges of this strip (Fig. 3) could be predicted from the particular illumination pattern used and the known axonal projection patterns for R1-R6 (Braitenberg, 1967). In other cases, the zone of damage clearly extended more widely than predicted from the directly illuminated patch. In all cases, the extent of damage in the lamina mirrored that in the retina. Sometimes the lamina contained a few large holes the size of one or more cartridges (Fig. 3), but inspection of the continuity of cartridge rows indicated that, though some cartridges next to a hole were extremely distorted, none were missing; the holes are therefore interpreted as the swelling and local inanition of single cells, possibly glial cells, to form a vacuole. Even in cases in which there was extreme destruction in the retina that might be interpreted as loss of complete ommatidia (Picaud et al., 1988), none of the lamina cartridges disappeared, even $14 \mathrm{~d}$ postillumination.

The darkened terminals could be seen easily by light microscopy (Fig. 3). Several types of degeneration could be identified from such material, as described below.

\section{Asynchrony of degeneration}

A perplexing early finding was that the zone of damage in the lamina of an individual fly had terminals manifesting different types of degeneration, even within a single cartridge (Fig. 4). This variegation is interpreted (see Discussion) as asynchrony in the degenerative changes among terminals; it confirms the findings of Griffiths and Boschek (1976) and occurred only up to postillumination times of $24 \mathrm{hr}$. Before this, the different stages of degenerating terminals coexisting at $1 \mathrm{hr}$ and $8 \mathrm{hr}$ postillumination were classified as belonging to three types.

Terminals were initially compared with a set of standardized electron micrographs of the three types of degeneration, according to various ultrastructural criteria: the degree of increase in cytoplasmic vacuolization and electron density; the stage of characteristic alteration in the size, number, and shape of mitochondrial profiles; and the appearance of their cristae. Later, the shrinkage of terminals was assayed by quantitative measurements of their perimeters; in addition, changes in the frequency of tetrad synapses were measured from counts of synaptic profiles. By comparison with a nondegenerated terminal (Fig. 5A), a type 1 degenerated terminal (Fig. $5 B$ ) showed a 


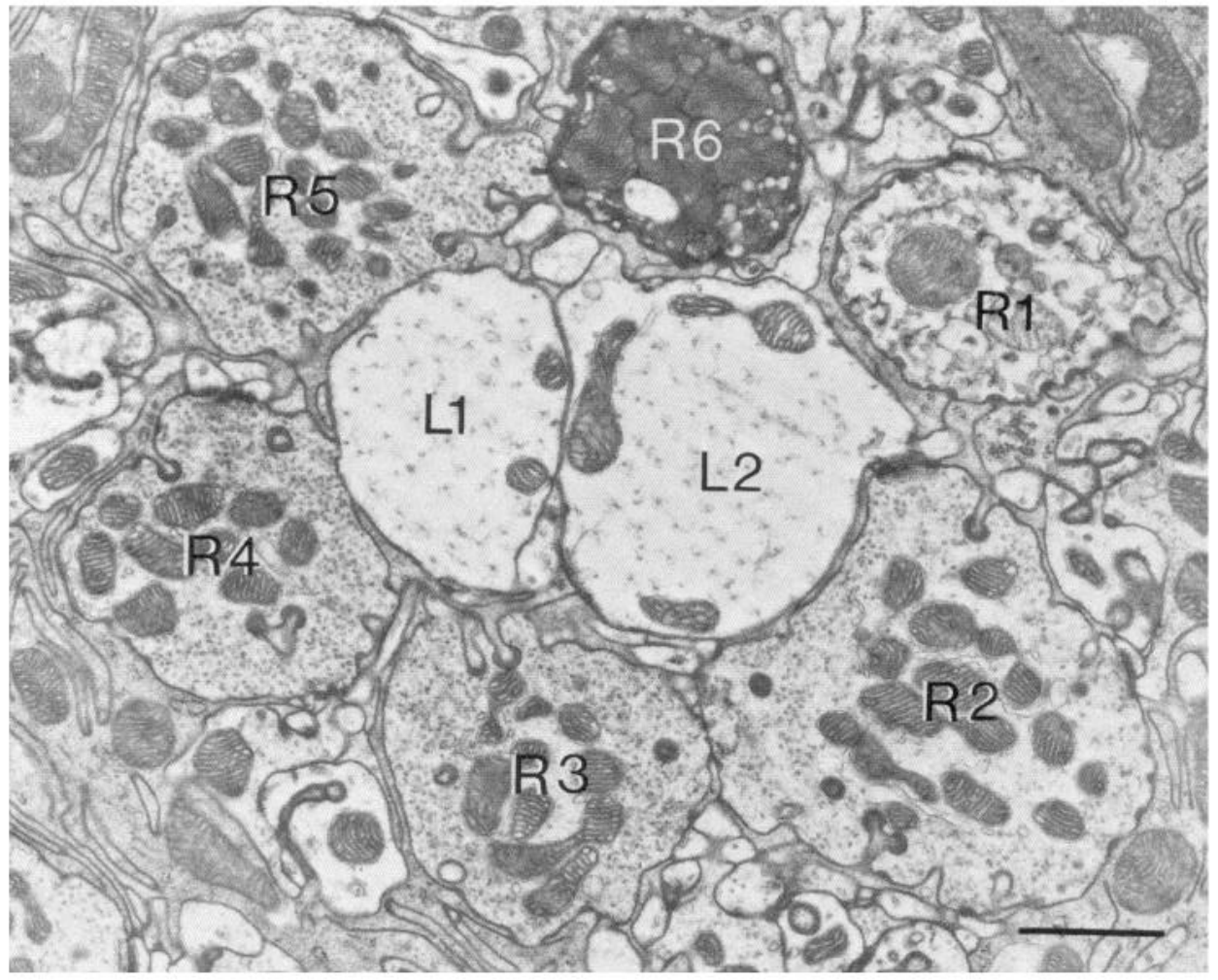

Figure 4. Cross section of an individual cartridge containing four normal receptor terminals with two others in different states of degeneration, surrounding the twin profiles of $L 1$ and $L 2$ at the core. Compared with the nondegenerating terminals $(R 2-R 5)$, terminal $R 1$ shows moderate signs of degeneration (type 1) with fewer and swollen mitochondria, increased cytoplasmic density and vacuolization, and a decrease in size, whereas the shrunken profile of terminal $R 6$, with completely dark cytoplasm, is in a final stage of degeneration (type 3). Magnification, $14,800 \times$. Scale bar, $1 \mu \mathrm{m}$. moderate increase in electron density, fewer synaptic vesicles and mitochondrial profiles, some having disrupted cristae, a number of membrane vesicles, and a decrease in size. The type 2 terminals (Fig. $5 \mathrm{C}$ ) showed a further increase in cytoplasmic electron density and vacuolization, a large number of round vesicles, large vacuoles, and swollen mitochondrial profiles with indistinct membranes and cristae. The type 3 degenerated terminals (Fig. $5 D$ ) were shrunk and completely dark, partially or largely surrounded by glial processes, and with a few abnormal, electron-dense mitochondrial profiles packed together at their centers. Measurements of the decreases in receptor terminal perimeters subsequently provided independent confirmation of the validity of these classes. Type 1 terminals were smaller by $13-19 \%$, type 2 by $22-27 \%$, and type 3 by $30-50 \%$ than their nondegenerated counterparts.

The relative frequencies of types 1-3 terminals are shown in Figure 6 and reveal an early preponderance of types 1 and 2. This was succeeded by a gradual accumulation of type 3 terminals, first evident at $24 \mathrm{hr}$ and lasting up to the latest period sampled (8d), between which times asynchrony of degeneration had disappeared. Because types 1-3 form a natural morphological progression with the type 3 terminals as the end point, and because the relative frequencies in laminae of increasing ages can be interpreted most economically as a temporal succession, we assume that each terminal that degenerates goes through all three stages. Particular cartridges identified in the middle of the lamina, and recognized again at a more proximal depth with respect to their positions in the patch of degeneration, had terminals each of which was the same (types 1-3) at the two depths, indicating that each terminal had only one type of degeneration, not several at different depths.

Two other types of degenerating terminals, less frequently observed, were not accompanied by increased electron density, one (Fig. 7A) resembling electron-lucent degeneration of a type first reported by de Robertis (1956), and the other (Fig. 7B) resembling neurofilamentous hyperplasia in vertebrates (Colonnier and Guillery, 1964; Arvidsson, 1986). The latter was found only after the longer postillumination periods sampled, starting at $48 \mathrm{hr}$ and especially after $8 \mathrm{~d}$ and $14 \mathrm{~d}$.

\section{Changes in the membrane perimeter of receptor terminals}

At longer postillumination times, the photoinjured terminals gradually deteriorated, as revealed by the increased cytoplasmic darkening. The membrane perimeters of the terminals also shrank (Fig. 6A). The different types of degenerating terminals at different postillumination periods showed a highly significant overall decrease in the membrane perimeter (Spearman correlation test, $p<0.01$ ), which was found at all ages. Although there was always a statistically highly significant difference between the undegenerated control terminals and the shrunken type $3 \mathrm{de}-$ generated terminals at $24 \mathrm{hr}$ or later, no significant further shrinkage of type 3 terminals was found with increasing postillumination times up to $8 \mathrm{~d}(p>0.05)$.

\section{Changes in the frequency of intact tetrad synapses}

Tetrad synapses can be recognized most readily in sections by their presynaptic ribbon, abutting two cisterna-containing central postsynaptic elements (Fig. $8 A, B$ ). The existence of cisternae was the criterion adopted to identify the postsynaptic elements. The number of intact synaptic complexes in the different types of degenerating terminals decreased with time (Fig. $6 B$ ), along with the shrinkage of the terminals' membrane perimeters (Fig. $6 A$ ). Although for the most part the decrease in frequency of intact synapses in the three different stages of degenerated terminals did not significantly differ $(p>0.05)$ when each stage was compared with the one adjacent to it (nondegenerated with 



Figure 5. Fine structural appearance of a normal terminal compared with three others in successive stages of degeneration. $A$, A nondegenerating receptor terminal, containing a large number of mitochondrial profiles $(\mathrm{m})$ and homogeneous round synaptic vesicles $(\mathrm{sv})$. $B$, Representative degenerating terminal (type 1) showing a moderate increase in electron density and vacuolization, reduced number of synaptic vesicles, altered mitochondria, and a modest decrease in size. $C$, Type 2 terminal showing a further increase in cytoplasmic electron density and vacuolization, fewer, much more swollen mitochondrial profiles with disrupted cristae (arrowhead), and a further decrease in size. $D$, Type 3 terminal, completely shrunk and dark with the few remaining abnormal mitochondria $(m)$ packed in the center of the terminal, which is bordered by increased incursions of epithelial glial cells $(\mathrm{g})$. Magnification, $19,000 \times$. Scale bar, $1 \mu \mathrm{m}$ for $A-D$.

type 1 , type 1 with type 2 , etc.), the overall decrease in synaptic frequency from nondegenerated to type 3 was always highly significant $(p<0.01)$. All intact synaptic complexes had completely disappeared by $24 \mathrm{hr}$ postillumination (Fig. $6 B$ ).

\section{Changes in the frequency of complete tetrads per unit membrane perimeter}

The terminals' membrane perimeters generally correlated closely with the number of intact tetrads, as gauged by the constancy of their quotient, the number of intact synaptic complexes per unit membrane perimeter (Fig. $6 \mathrm{C}$ ). There was no significant change in this density up to $8 \mathrm{hr}$ postillumination $(p>0.1)$, except for the most advanced (type 3 ) degenerated terminals at $8 \mathrm{hr}$ postillumination, for which it showed a marked and statistically highly significant drop $(p<0.01)$, to 0.06 synaptic profiles per micron of membrane perimeter. Before this, at times up to $8 \mathrm{hr}$ postillumination, a synaptic spacing density of about 0.2 profiles per micron was maintained, similar to that found in the nondegenerated control terminals (average also 0.20 profiles $/ \mu \mathrm{m})$. There was also no difference in synaptic spacing densities between nondegenerated control terminals at different times postillumination $(p>0.2$; Fig. $6 C)$.

Figure 6. Histograms summarizing the changes found in receptor terminals at postillumination times from $1 \mathrm{hr}$ to $8 \mathrm{~d}$ (vertical columns). Bars within each histogram are terminals segregated into those that are nondegenerated (non deg) and those for the three types of degenerating terminals (deg 1-deg 3) described in Results. Numbers within each histogram bar give the number of terminals sampled. Histograms should be compared from left to right to reveal their temporal succession. $A$, The perimeter of receptor terminal profiles at different postillumination times. $B$, The number of intact synaptic complexes retaining both presynaptic ribbon and two cisterna-bearing median postsynaptic elements. $C$, The number of intact synaptic complexes in $B$, recalculated per micron of terminal membrane perimeter (from $A$ ). $D$, The number of synaptic sites lacking a presynaptic ribbon but with both cisterna-bearing postsynaptic elements still attached to the presynaptic site. $E$, The number of synaptic sites lacking a presynaptic ribbon and with two cisterna-bearing postsynaptic elements withdrawn from the presynaptic receptor terminal. Values are means $\pm \mathrm{SD}$; significance levels: ${ }^{* *}, p<0.05$; $^{* * *}, p<0.01$. 

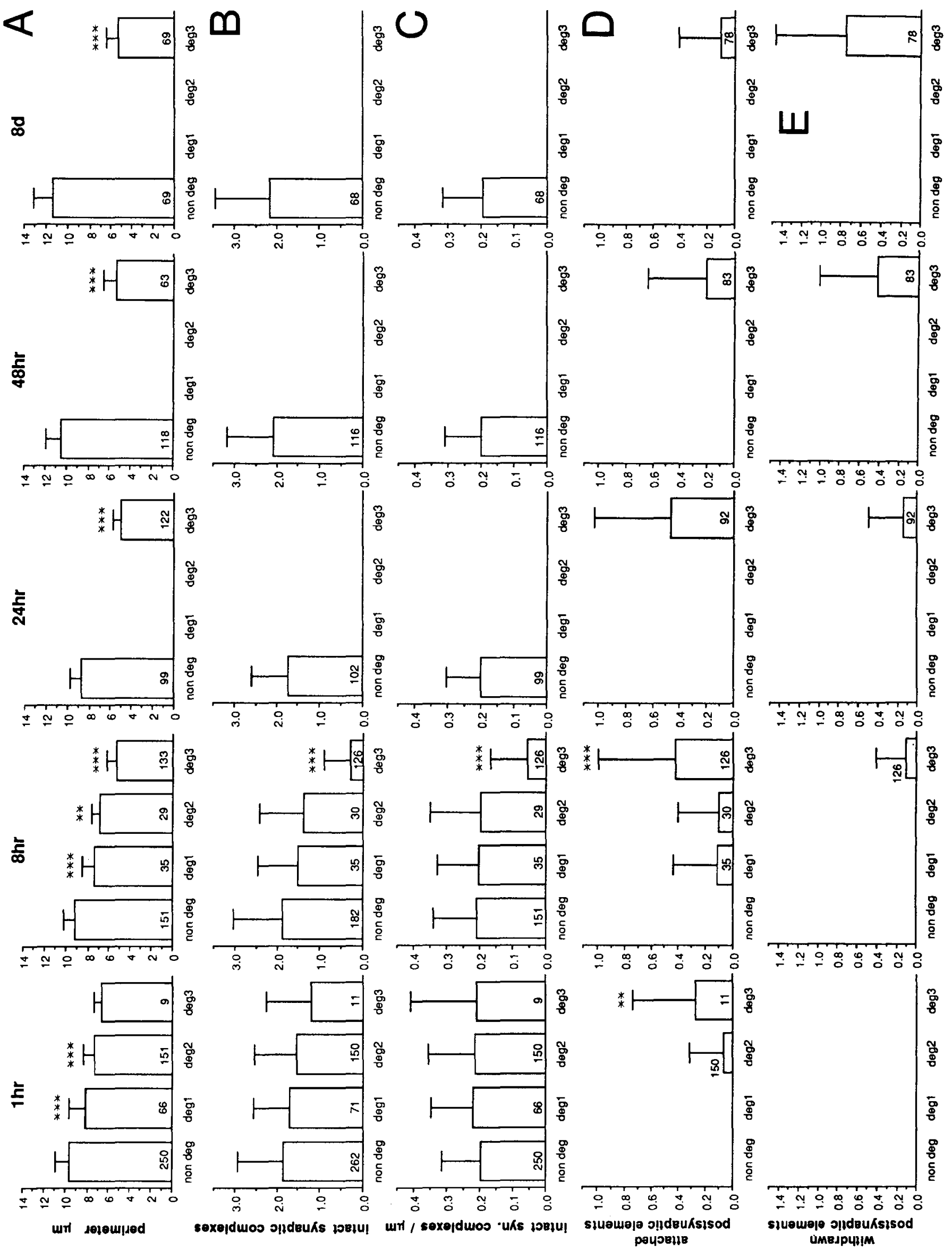

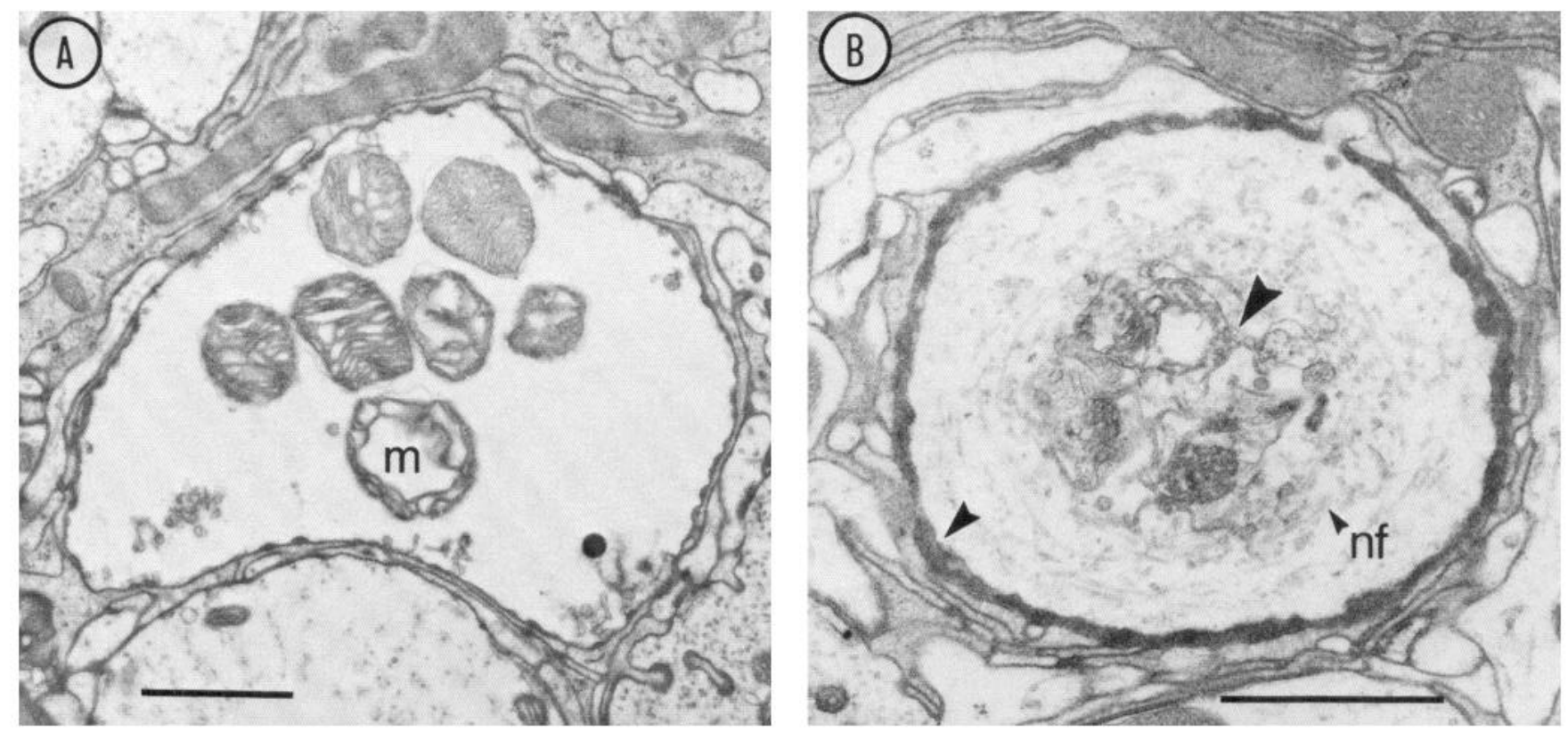

Figure 7. A, A swollen terminal showing electron-lucent degeneration. Note the clear cytoplasm and complete loss of synaptic vesicles. Mitochondrial profiles $(m)$ are few, swollen, and with cristae showing clear signs of disintegration. Magnification, $16,500 \times$. Scale bar, $1 \mu \mathrm{m}$. $B$, A terminal interpreted as showing neurofilamentous hyperplasia, with bundles of neurofilaments $(n f)$ circularly arranged. Note also the clumping of disintegrated structures (large arrowhead), probably mitochondrial profiles, in the center, and the thick electron-dense outlines (small arrowhead) of the terminal. Magnification, $25,400 \times$. Scale bar, $1 \mu \mathrm{m}$.

\section{Dynamic events in the loss of tetrad synapses}

When a photodegenerated terminal had shrunk somewhat and showed ultrastructural darkening, the T-shaped presynaptic ribbons of the tetrads were usually still visible (Fig. $8 B$ ), though some had disappeared. At later stages when the cytoplasm appeared very dark, the presynaptic ribbons were no longer discernible and presumably had been lost (Fig. 8C). In this first stage of discernible synaptic loss, the postsynaptic elements with their cisternae still lay closely abutting the terminal at the presumed original synaptic site. The frequency of synaptic sites at which the presynaptic ribbon was not visible and presumed lost, but where the postsynaptic elements still closely abutted the presynaptic membrane (Fig. $8 C, D$ ), gradually increased up to $24 \mathrm{hr}$ postillumination, peaked, then decreased thereafter until $8 \mathrm{~d}$ postillumination (Fig. $6 \mathrm{D}$ ).

In what may be interpreted as the next step, a synaptic site that is presumed to have already lost its presynaptic ribbon next loses contact with its postsynaptic elements (Fig. $8 E$ ), and glial processes insinuate between erstwhile pre- and postsynaptic membranes. Eventually, the postsynaptic tetrad withdraws from such sites as an ensemble, with the cisternae in the two median elements of the tetrad, L1 and L2 (Nicol and Meinertzhagen, 1982), still distinguishable (Fig. $8 F$ ). In a final stage, the two cisterna-bearing elements separate from one another (Fig. 9E).

These stages have been assembled into an entire hypothetical sequence, reconstructed from individual junctions, as illustrated in Figure 9.

\section{Discussion}

In this study, we have used light irradiation and the eye's own optics to procure the degeneration of photoreceptors. The use of optical methods to ablate neurons or their parts has been exploited in a number of ways in neurobiology, because of the superior spatial and temporal localization that these methods offer over conventional surgery. In functional studies, photoablation has been used to dissect neural networks in crickets (Jacobs and Miller, 1985) and leeches (Lytton and Kristan, 1989), where its use on dye-filled neurons increases localization by minimizing damage to neighboring cells. In developmental studies, high-intensity microbeams have been widely used to delete growing neurons or their progenitors (Sulston and White, 1980; Berns et al., 1981; Geiger et al., 1983), but with interest directed to the survivors, rather than the irradiated cells.

Figure 8. Fine structure of synaptic contacts arranged in a progressive sequence $(A-F)$ of disassembly. $A$, Normal synaptic ensemble with two postsynaptic elements, bearing cisternae (arrowheads), abutting the table-shaped presynaptic ribbon (open arrow), from a nondegenerating terminal. $B$, From a terminal starting to degenerate, a similar ensemble not yet showing any structural changes but with glial cell processes $(g)$ starting to interpolate between pre- and postsynaptic partners. $C$ and $D$, Degenerating terminals lacking presynaptic ribbons (asterisks), but with postsynaptic elements, indicated by the presence of cisternae (arrowheads), still closely abutting the original synaptic site. $E$, Postsynaptic elements with cisternae (arrowheads), that have lost contact with the degenerating presynaptic terminal (asterisk), and glial process $(g)$ that has insinuated between preand postsynaptic membranes more extensively than in $D$. F, Postsynaptic elements, with cisternae (arrowheads), that have completely withdrawn as an ensemble from the degenerating terminal (asterisk), and glia $(g)$ that separate the former synaptic partners. Magnification, 104,000. Scale bar, $0.2 \mu \mathrm{m}$ for $A-F$. 

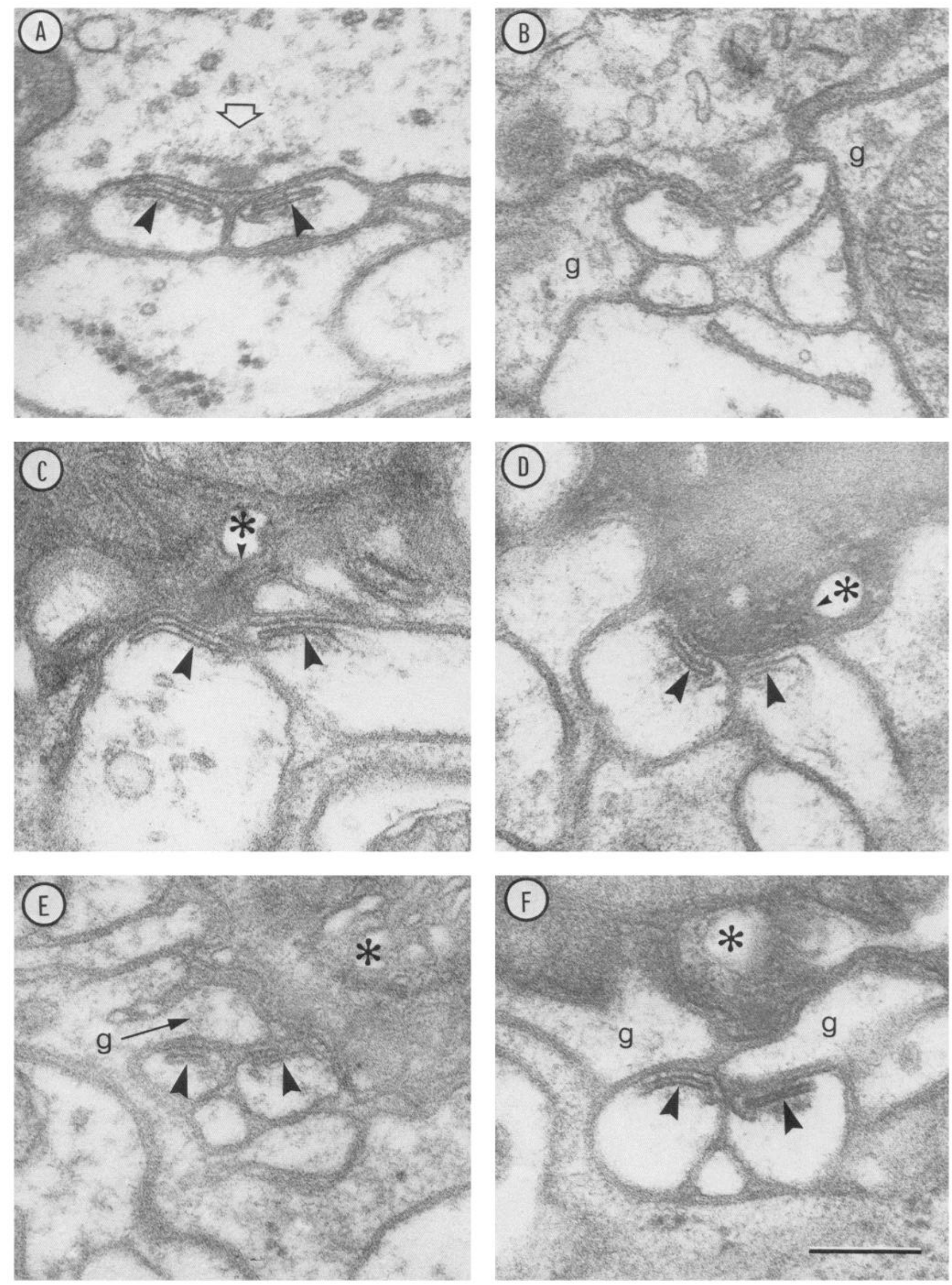
Figure 9. Summary diagram of the disassembly sequence at a single afferent tetrad site, as suggested by our observations. $A$, A normal terminal with intact synapses having both presynaptic ribbons and postsynaptic elements. $B$, A terminal showing first obvious signs of degeneration but still having both presynaptic ribbons and postsynaptic elements, $C, \mathrm{~A}$ degenerating terminal in which some synapses have lost presynaptic ribbons but at which the postsynaptic elements with their cisternae still closely abut the original presynaptic site. $D$, A subsequent stage of degeneration, in which the entire postsynaptic ensemble has separated, accompanied by insinuation of glial cell processes $(g)$ between pre- and postsynaptic partners. $E$, The last stage of disassembly that can be recognized by EM: the two cisterna-bearing postsynaptic elements separate from one another.
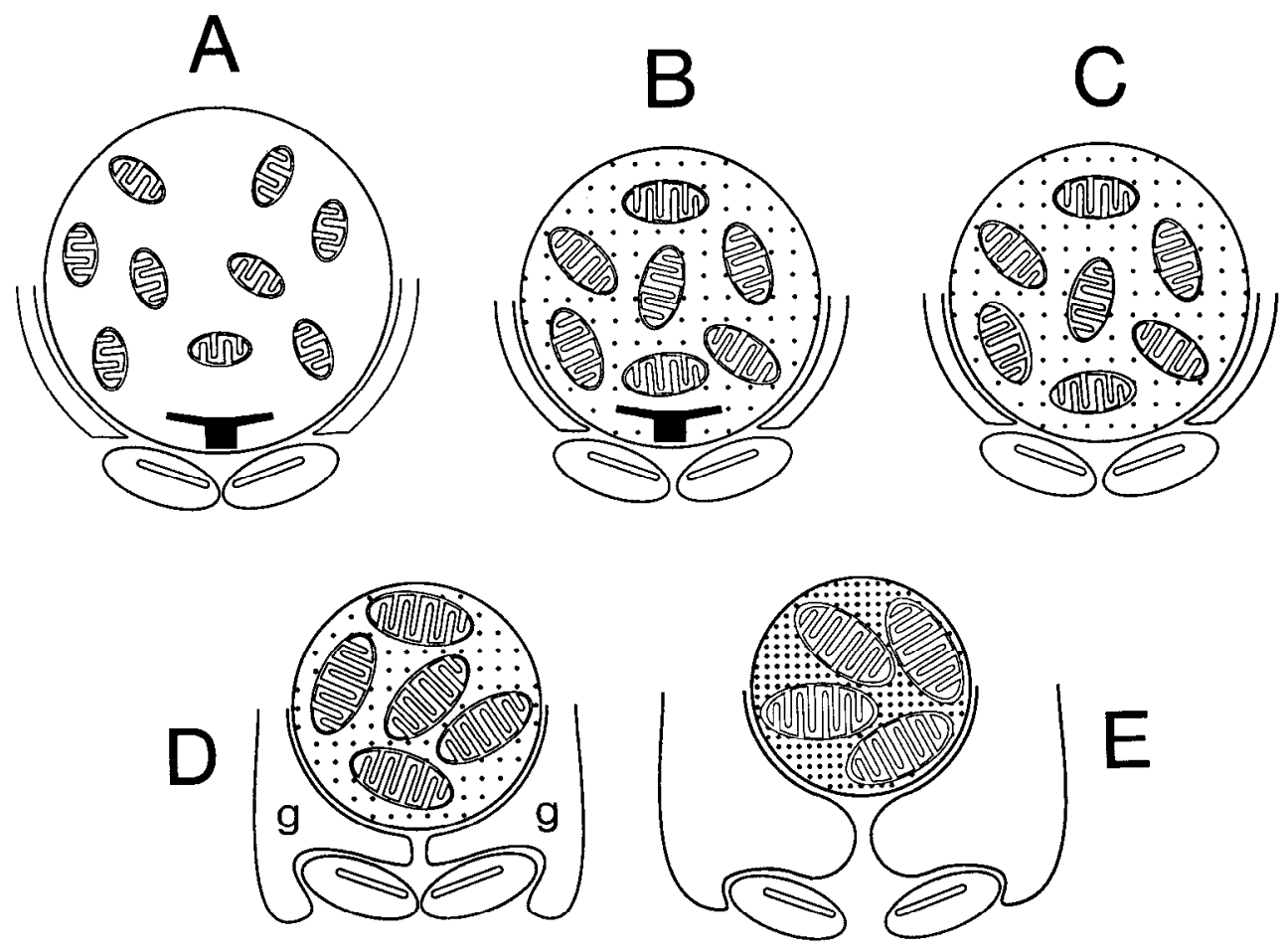

The onset of degeneration within a 12-min period allows us to trace the dynamics of the disappearance of tetrad synapses from receptor terminals in the lamina. Initially, we had anticipated that degenerative events would have been more synchronized, at least within an individual synaptic terminal, but it is now clear that at least three sets of dynamic events are involved: asynchronous degeneration of the terminals of simultaneously irradiated cells, asynchrony of synaptic loss from individual terminals, and sequential disassembly at individual sites. Each is discussed in turn below.

\section{Receptor terminal degeneration}

The fine structure of anterograde degeneration following neuronal injury has been widely documented in neurons following surgical (e.g., Guillery, 1970) or neurotoxic treatments (Malmfors and Thoenen, 1971; Jonsson, 1980). Degenerative changes seen not only in injured neurons (Guillery, 1970) but also transsynaptically (e.g., Cowan, 1970; Knyihar-Csillik and Csillik, 1987), fall into three main types, all of which have been seen in the fly's photoreceptor terminals: electron dense, electron lucent, and filamentous hyperplasia. Neither of the latter two are thought to be closely linked to the type 1-3 progression of electron-dense degeneration, and filamentous hyperplasia was seen only following long retrieval periods postillumination. The type 1-3 changes described here extend in the time domain those seen by Picaud et al. (1988) and are similar to those in other insect (Schürmann, 1980) and crustacean (Hámori and Horridge, 1966) tissues. The darkening response in receptor terminals in the fly was first reported as a reaction to electrocoagulation (Campos-Ortega and Strausfeld, 1972); its rapidity is remarkable, with darkened terminals appearing in the lamina only a few minutes after cuts made in the retina (Griffiths and Boschek, 1976). At the other temporal extreme, a few rhabdomeres and terminals may degenerate naturally in old Drosophila (Stark et al., 1988).
The most puzzling finding of this study is the coexistence of different types of degenerated terminals, even within a single cartridge. In some cases these must have arisen from the small central patch of receptors all receiving the same amount of direct illumination. A few terminals reach an advanced stage of degeneration within $1 \mathrm{hr}$, whereas many others fail to do so even by $8 \mathrm{hr}$, differences not attributable to the terminals exhibiting different types of degeneration at variable depths in the lamina. The different types evidently represent different stages in the time course of a single process of degeneration, which must therefore occur asynchronously among terminals. Parallel observations of asynchrony come from visual system mutants in Drosophila, in which different stages of receptor terminal degeneration have previously been observed in Drosophila mutants $r d g A$ (Stark and Carlson, 1985) and $r d g B$ (quantified in Minke et al., 1990), and occasional nonuniform degeneration is found in the lamina of norpA (Stark et al., 1989). Asynchrony of degeneration is also apparent in the double mutant $r d g B$; Acph (Stark and Sapp, 1989, their Fig. 31).

On the face of it, degeneration in terminals must occur either with different thresholds, or with different latencies in different cells, or with a constant threshold among cells that absorb differing amounts of light. Differential absorption among R1-R6 in the directly illuminated ommatidia seems unlikely, given the uniformly illuminated field and that during the 12-min photolesion the rhabdomeres of R1-R6 all drastically changed appearance simultaneously (Fig. 2). Entoptic light scatter could in principle explain the asynchrony of degeneration between terminals that received stray light at the edge of the zone of direct illumination because ommatidia did fluoresce somewhat outside the spot during intense illumination (Fig. 2). Lateral light leakage inside the eye is therefore not negligible and may have exceeded the presumed threshold for photodegeneration for some nearby cells. Such scatter cannot have been a major factor in the one case examined in detail, however, in which lamina 
degeneration was confined to the area of direct illumination. On the other hand, some of our other lesions did extend beyond the zone of direct illumination. It is unclear why the sizes of lesion are larger in these cases, but we suspect that the concentration of dye at the time of illumination may have been higher because the postinjection interval was not uniform in our experiments. Time constants of 45-80 min for the clearance of different dyes from the retina (Weyrauther et al., 1989) are sufficiently short to have varied the sulforhodamine concentration considerably between our animals through postinjection clearance from the eye, by the time photoablation was commenced.

\section{Loss of synapses}

Asynchronous loss of each terminal's synaptic population (Fig. 6) was unexpected. Intact synaptic junctions coexist with ones that are interpreted as just having separated, raising questions about how some sites survive within a terminal that is rapidly losing others. It may be that a turnover of synaptic sites exists normally, for which the formation rate can be rapid (Rybak and Meinertzhagen, 1990), that turnover continues postillumination, but that no new presynaptic sites can form in a photodegenerating terminal. The rate of loss appearing during degeneration might then simply be the now unbalanced rate of loss occurring normally, but if so, it is unclear why all sites would not be relinquished synchronously. It might be that asynchrony is inherent, if for example different synapses were at different points of a maturation cycle at the time of their receptor's illumination. Whatever the case, the asynchrony implies a strong autonomy at individual sites within one terminal, of the synaptoclastic interactions between pre- and postsynaptic elements.

Following the initial loss of its presynaptic sites, a receptor terminal still seems to regulate the normal spacing of its surviving sites actively, as revealed by their number per micron of terminal membrane, presumably by the same mechanisms as exist in intact cells (Nicol and Meinertzhagen, 1982). This regulation breaks down only in the type 3 stage of degeneration at $8 \mathrm{hr}$, when synaptic loss suddenly outstrips terminal membrane.

\section{Disassembly of individual junctions}

Disassembly at individual synaptic sites is sequential (Fig. 8), involving apparently first the loss of the presynaptic ribbon, then separation of the entire postsynaptic ensemble, accompanied by insinuation of a glial cell process between former preand postsynaptic partners (Fig. 9). The evidence for this sequence rests on the plausible morphological series into which the steps can be arranged, and upon the temporal succession of their frequencies, in animals with increasing postillumination intervals. Even at $1 \mathrm{hr}$ postillumination, the absolute number of synaptic profiles with intact presynaptic ribbons is reduced, and by $8 \mathrm{hr}, 85 \%$ of type 3 terminals have lost their ribbons (Fig. $6 \mathrm{~B}$ ); in contrast, no withdrawal of postsynaptic elements from these same sites was observed at $1 \mathrm{hr}$, and very little even by $8 \mathrm{hr}$ (Fig. $6 E$ ), supporting the notion that postsynaptic loss may be triggcred sequentially from presynaptic change. Overall, from $1 \mathrm{hr}$ postillumination until $8 \mathrm{~d}$ (Fig. 6), there is a monotonic increase both in the number of synaptic sites at which the ribbon is no longer discernible and in the withdrawal of postsynaptic elements from these sites. There is some lag of withdrawal with respect to disappearance of the ribbon (Fig. $6 D, E$ ), as expected if loss of the ribbon were the prerequisite for withdrawal. Finally, we never found a single degenerating synaptic site with its postsynaptic elements withdrawn from the presynaptic site but with its presynaptic ribbon intact, the strongest confirmation of the sequence of events outlined above and one that suggests that dismantling starts at the presynaptic site following photodegeneration. Although the disassembly sequence may be triggered by the ribbon's breakdown, the increased cytoplasmic electron opacity of this typc of degencration obscures the ribbon and has so far hindered our observing stages in its breakdown.

Disjunction has been observed at other synapses incorporating a degenerating cell, but in motor systems and with findings that are the reciprocal of ours. In motoneuron cell bodies (Blinzinger and Kreutzberg, 1968) and in sympathetic ganglion cell dendrites (Matthews and Nelson, 1975; Purves, 1975), detachment and retraction have been observed, but for presynaptic endings from their degenerating postsynaptic targets. Is this difference one of kind, say, between synapses of sensory and motor systems? That conclusion would be premature until comparison is made between the complementary denervation experiments: (1) degenerating the inputs to a motoneuron, and (2) degenerating the postsynaptic neurons of the sensory synapse, here Ll and L2. For the first comparison, it has been widely reported that preganglionic axotomy results in degenerative loss of a motoneuron's inputs, with the long-term retention of intact, vacated postsynaptic specializations (e.g., Raisman et al., 1974). In contrast, we found that postsynaptic sites are retained for much shorter periods in the fly's L1 and L2, whose dendrites always separate from the presynaptic site. Experiments are under way to examine the second above-mentioned comparison, by axotomy of $\mathrm{L} 1$ and L2, and further comparison is currently not possible. Nevertheless, we propose that in both sensory and motor cases the retraction of a synaptic partner depends upon which partner, pre- or postsynaptic, is normally actively maintained in synaptic apposition. At motor synapses, it is the presynaptic terminal boutons, and in the sensory synapses investigated here, the slender postsynaptic spines of L1 and L2. The presynaptic terminals at motor synapses are widely interpreted to be maintained by the supply of trophic factors from their targets (Purves, 1988); possibly the reverse occurs in the lamina synapse, with the supply of a factor from the photoreceptor terminal. Although this possibility is at first sight countersuggested by the lack of transsynaptic degeneration in Ll/L2 for even $14 \mathrm{~d}$ postillumination, these cells do have other inputs in the lamina (Strausfeld and Campos-Ortega, 1977) that could sustain them in the face of lost receptor inputs. The suggested dependency on trophic factors from receptor terminals would also correlate with which element actively grows to the other during the formation of synapses. In motor synapses, the presynaptic axon grows to the presumptive postsynaptic site (as in the neuromuscular junction; Dennis, 1981), whereas for many sensory synapses (e.g., the triad synapse of the mouse's retina; Blanks et al., 1974), this sequence is reversed. In the fly's lamina, though initial ingrowth of receptor axons brings them in contact with their lamina target cells (Meinertzhagen, 1973), synaptogenesis is initiated only later, by outgrowth of spines from L1/ L2 over the receptor terminals' surfaces (Fröhlich and Meinertzhagen, 1983).

Epithelial glial cell processes, which everywhere surround the neurons of the cartridge and their synapses (Boschek, 1971; Saint Marie and Carlson, 1983), hypertrophy following receptor degeneration, as previously noted in Drosophila (Stark and Carlson, 1984). Thus, they adopt a similar role to that of glia elsewhere during degenerative loss. For example, glial cells are involved in the degenerative loss of receptor terminals of the 
lobster's optic lamina (Hamori and Horridge, 1966), while in vertebrates microglia displace synaptic boutons following motoneuron axotomy during target deafferentation (Blinzinger and Kreutzberg, 1968). In the inner plexiform layer of the retina, glial appositions likewise insinuate at bipolar cell dyads following the degenerative loss of an indoleaminergic element (Ehinger and Holmgren, 1979). Glial invasion in the fly's lamina is progressive, sometimes manifesting early (Fig. $8 B$ ), and becoming universal at synaptic sites late in the sequence of degenerative change (Fig. 9D,E).

Adhesion between the two median elements of the postsynaptic ensemble at the fly's afferent synapse clearly continues after their separation from the presynaptic site. Tight adhesion of synaptic elements elsewhere may be maintained even after gross insult, as in synaptosome fractions after tissue homogenization (Whittaker, 1987), though in that case adhesion is between the presynaptic element and its postsynaptic partner. The adhesion between synaptic elements found here, between the postsynaptic elements of a multiple-contact synapse, likewise represents the maintenance into maturity of the original intercellular recognition by which the synapse first formed, a recognition hitherto only presumed, based on the ontogenetic sequence of assembly of postsynaptic cells into the tetrad group (Meinertzhagen, 1984)

\section{Reterences}

Arvidsson J (1986) Transganglionic degeneration in vibrissae innervating primary sensory neurons of the rat: a light and clcetron microscopic study. J Comp Neurol 249:392-403.

Barker D, Ip MC (1966) Sprouting and degeneration of mammalian motor axons in normal and deafferentated skeletal muscle. Proc $R$ Soc Lond Ser B 163:538-554.

Berns MW, Aist J, Edwards J, Strahs K, Girton J, McNeill P, Rattner JB, Kitzes M, Hammer-Wilson M, Liaw L-H, Siemans A, Koontz M, Peterson S, Brenner S, Burt J, Walter R, Bryant PJ, Van Dyk D, Coulombe J, Cahill T, Berns GS (1981) Laser microsurgery in cell and developmental biology. Science 213:505-513.

Blanks JC, Adinolfi AM, Lolley RN (1974) Synaptogenesis in the photoreceptor terminal of the mouse retina. J Comp Neurol 156:8194.

Blinzinger K, Kreutzberg G (1968) Displacement of synaptic terminals from regencrating motoncurons by microglial cclls. Z Zellforsch 85 : $145-157$.

Boschek CB (1971) On the fine structure of the peripheral retina and lamina ganglionaris of the fly, Musca domestica. Z Zellforsch 118 : 369-409.

Braitenberg V (1967) Patterns of projection in the visual system of the fly. I. Retina-lamina projections. Exp Brain Res 3:271-298.

Campos-Ortega JA, Strausfeld NJ (1972) The columnar organization of the second synaptic region of the visual system of $M$ usca domestica. Z Zellforsch 124:561-585.

Colonnier M, Guillery RW (1964) Synaptic organization in the lateral geniculate nucleus of the monkey. Z Zellforsch 62:333-355.

Cotman CW, Nieto-Sampedro M, Harris EW (1981) Synapse replacement in the nervous system of adult vertebrates. Physiol Rev 61:684784.

Cowan WM (1970) Anterograde and retrograde transneuronal degeneration in the central and peripheral nervous system. In: Contemporary research methods in neuroanatomy (Nauta WJH, Ebbesson SOE, eds), pp 217-249. New York: Springer.

de Robertis E (1956) Submicroscopic changes of the synapse after nerve section in the acoustic ganglion of the guinea pig. An electron microscope study. J Biophys Biochem Cytol 2:503-519.

Dennis M.J (1981) Development of the neuromuscular junction: inductive interactions between cells. Annu Rev Neurosci 4:43-68.

Ehinger B, Holmgren I (1979) Electron microscopy of the indoleamine-accumulating neurons in the retina of the rabbit. Cell Tissue Res 197:175-194.
Franceschini N, Kirschfeld K (1971) Etude optique in vivo des éléments photorécepteurs dans l'oeil composé de Drosophila. Kybernetik $8: 1-13$.

Fröhlich A (1985) Freeze-fracture study of an invertebrate multiplecontact synapse: the fly photoreceptor tetrad. J Comp Neurol 241: 311-326.

Fröhlich A, Meinertzhagen IA (1982) Synaptogenesis in the first optic neuropile of the fly's visual system. J Neurocytol 11:159-180.

Fröhlich A, Meinertzhagen IA (1983) Quantitative features of synapse formation in the fly's visual system. I. The presynaptic photoreceptor terminal. J Neurosci 3:2336-2349.

Geiger G, Nässel DR, Seyan HS (1983) Laser microsurgery for the study of behaviour and neural development of flies. In: Functional neuroanatomy (Strausfeld NJ, ed), pp 206-224. Heidelberg: Springer.

Greenough WT, Chang F-LF (1985) Synaptic structural correlates of information storage in mammalian nervous systems. In: Synaptic plasticity (Cotman CW, ed), pp 335-372. New York: Guilford.

Griffiths GW, Boschek CB (1976) Rapid degeneration of visual fibers following retinal lesions in the dipteran compound eye. Neurosci Lett 3:253-258.

Guillery RW (1970) Light- and electron microscopical studics of normal and degenerating axons. In: Contemporary research methods in neuroanatomy (Nauta WJH, Ebbesson SOE, eds), pp 77-105. New York: Springer.

Hámori J, Horridge GA (1966) The lobster optic lamina. III. Degeneration of retinula cell endings. J Cell Science 1:271-274.

Hardie RC (1985) Functional organization of the fly retina. In: Progress in sensory physiology, Vol 5 (Ottoson D, ed), pp 1-79. New York: Springer.

Herrera AA, Banner LR, Nagaya N (1990) Repeated, in vivo observation of frog neuromuscular junctions: remodelling involves concurrent growth and retraction. J Neurocytol 19:85-99.

Jacobs GA, Miller JP (1985) Functional properties of individual neuronal branches isolated in situ by laser photoinactivation. Science 228:344-346.

Jonsson G (1980) Chemical neurotoxins as denervation tools in neurobiology. Annu Rev Neurosci 3:169-187.

Knyihar-Csillik E, Csillik B (1987) Degeneration, transneuronal. In: Encyclopedia of neuroscience (Adelman G, ed), pp 308-309. Boston: Birkhäuser.

Lytton WW, Kristan WB (1989) Localization of a leech inhibitory synapse by photo-ablation of individual dendrites. Brain Res 504: 43-48.

Malmfors, T, Thoenen T (1971) 6-Hydroxydopamine and catecholamine neurons. New York: Elsevier.

Matthews MR, Nelson VH (1975) Detachment of structurally intact nerve endings from chromatolytic neurones of rat superior cervical ganglion during the depression of synaptic transmission induced by post-ganglionic axotomy. J Physiol (Lond) 245:91-135.

Meinertzhagen IA (1973) Development of the compound eye and optic lobe of insects. In: Developmental neurobiology of arthropods (Young $\mathrm{D}$, ed), pp 51-104. Cambridge: Cambridge UP.

Meinertzhagen IA (1984) The rules of synaptic assembly in the developing insect lamina. In: NATO Advanced Science Institutes, Ser A, Vol 74, Photoreception and vision in invertebrates (Ali MA, ed), pp 635-660. New York: Plenum.

Meinertzhagen IA (1989) Fly photoreceptor synapses: their development, evolution, and plasticity. J Neurobiol 20:276-294.

Meinertzhagen IA, Fröhlich A (1983) The regulation of synapse formation in the fly's visual system. Trends Neurosci 6:223-228.

Minke B, Rubinstein CT, Sahly I, Bar-Nachum S, Timberg R, Selinger $Z$ (1990) Phorbol ester induces photoreceptor-specific degeneration in a Drosophila mutant. Proc Natl Acad Sci USA 87:113-117.

Nicol D, Meinertzhagen IA (1982) An analysis of the number and composition of the synaptic populations formed by photoreceptors of the fly. J Comp Neurol 207:29-44.

Picaud S, Wunderer HJ, Franceschini N (1988) 'Photo-degeneration' of neurones after extracellular dye application. Neurosci Lett 95:24 30.

Picaud S, Wunderer H, Franceschini N (1990) Dye-induced photopermeabilization and photodegeneration: a lesion technique useful for neuronal tracing. J Neurosci Methods 33:101-112.

Purves D (1975) Functional and structural changes in mammalian sympathetic neurones following interruption of their axons. J Physiol (Lond) 252:429-463. 
Purves D (1988) Body and brain: a trophic theory of nerve connections. Cambridge, MA: Harvard UP.

Raisman G, Field PM, Östberg AJC, Iverson LL, Zigmond RE (1974) A quantitative ultrastructural and biochemical analysis of the process of reinnervation of the superior cervical ganglion in the adult rat. Brain Res 71:1-16.

Rybak J, Meinertzhagen IA (1990) Expcriencc-dependent changcs in the sizes and frequencies of photreceptor synapses in the fly's optic lamina. In: Proceedings of the 18th Göttingen neurobiology meeting, Brain-perception-cognition (Elsner N, Roth G, eds), p 196. Stuttgart: Thieme.

Sachs L (1984) Angewandte Statistik. New York: Springer.

Saint Marie RL, Carlson SD (1983) The fine structure of neuroglia in the lamina ganglionaris of the housefly, Musca domestica L. J Neurocytol 12:213-241.

Schürmann F-W (1980) Experimental anterograde degeneration of nerve fibers: a tool for combined light- and electron-microscopic studies of the insect nervous system. In: Neuroanatomical techniques (Strausfeld NJ, Miller TA, eds), pp 263-281. New York: Springer

Shaw SR (1990) The photoreceptor axon projection and its evolution in the neural superposition eyes of some primitive brachyceran Diptera. Brain Behav Evol 35:107-125.

Stark WS, Carlson SD (1984) Blue and ultraviolet light induced damage to the Drosophila retina: ultrastructure. Curr Eye Res 3:14411454.

Stark WS, Carlson SD (1985) Retinal degeneration in rdgA mutants of Drosophila melanogaster (Diptera: Drosophilidae). Int J Insect Morphol Embryol 14:243-254.

Stark WS, Sapp R (1989) Retinal degeneration and photoreceptor maintenance in Drosophila: $r d g B$ and its interaction with other mutants. In: Inherited and environmentally induced retinal degeneration
(La Vail MM, Anderson RE, Hollyfield JG, eds), pp 467-489. New York: Liss.

Stark WS, Sapp R, Schilly D (1988) Rhabdomere turnover and rhodopsin cycle: maintenance of retinula cells in Drosophila melanogaster. J Neurocytol 17:499-509.

Stark WS, Sapp R, Carlson SD (1989) Photoreceptor maintenance and degeneration in the norpA (no receptor potential-A) mutant of Drosophila melanogaster. J Neurogenet 5:49-59.

Strausfeld NJ, Campos-Ortega JA (1977) Vision in insects: pathways possibly underlying neural adaptation and lateral inhibition. Science 195:894-897.

Sulston JE, White JG (1980) Regulation and cell autonomy during postembryonic development of Caenorhabditis elegans. Dev Biol 78 : 577-597.

Wernig A, Herrera AA (1986) Sprouting and remodelling at the nervemuscle junction. Prog Neurobiol 27:251-291.

Weyrauther E, Roebroek JGH, Stavenga DG (1989) Dye transport across the retinal basement membrane of the blowfly Calliphora erythrocephala. J Exp Biol 141:47-59.

Whittaker VP (1987) Synaptosome. In: Encyclopedia of neuroscience (Adelman G, ed), pp 1179-1181. Boston: Birkhäuser.

Wilcox M, Franceschini N (1984a) Illumination induces dye incorporation in photoreceptor cells. Science 225:851-854.

Wilcox M, Franceschini N (1984b) Stimulated drug uptake in a photoreceptor cell. Neurosci Lett 50:187-192.

Wunderer H, Picaud S, Franceschini N (1989) Selective illumination of single photoreceptors in the house fly retina: local membrane turnover and uptake of extracellular horseradish peroxidase (HRP) and Lucifer yellow. Cell Tissue Res 257:565-576.

Wyszecki G, Stiles WS (1967) Color science. New York: Wiley. 